\begin{tabular}{cc}
\hline \\
Journal of Modern Economy \\
(ISSN:2577-8218)
\end{tabular}

\title{
On the sustainable economy development of some European Countries
}

\section{Nicholas S. Gonchar*, Olena P. Dovzhyk}

Mathematical Modeling Laboratory of Synergetics Department, the N.N.Bogolyubov Institute for Theoretical Physics, Kiev, Ukraine

\begin{abstract}
A new method to investigate the equilibrium state of an economy is proposed. The classification of the equilibrium states is given. The basic principle of equilibrium the economy to its environment is formulated. It is used to obtain the money circulation equation. On this basis the notion of the sustainable economic development is defined. The analysis of the economy of three European contries is given. The principle of adequacy of currency exchange and inflation rates to the determining factors is proposed.

Keywords: Exchange Rate, Forcast, Sustainable Economy Development, Recession

This work was supported in part by the Program of Fundamental Research of the National Academy of Sciences of Ukraine (project № 0118U003196).
\end{abstract} ${ }^{*}$ Correspondence to Author: Nicholas S. Gonchar

Mathematical Modeling Laboratory of Synergetics Department, the N.N.Bogolyubov Institute for Theoretical Physics, Kiev, Ukraine

How to cite this article:

Nicholas S. Gonchar, Olena P. Dovzhyk. On the sustainable economy development of some European Countries.Journal of Modern Economy, 2022,5:14.

\section{eScîPub} eSciPub LLC, Houston, TX USA. Website: https://escipub.com/ 


\section{Introduction}

This paper continues the papers ${ }^{[1,2]}$ in which we were formulated the principle of the sustainable economic development. The purpose of the paper using the above principle of the sustainable economy development to investigate the closeness of the economy system to the recession state for three European countries. As it was shown one of the author in the papers $[3,4,5,6,7]$ the closeness to the recession state is characterized by the quality of the economy equilibrium. If the degeneracy multiplicity of the economy equilibribrium state is not high then we can say about the sustainable economy development. In case if the degeneracy multiplicity is high then it means that the demand for the determining group of goods is low. With the sufficiently low demand for the determining group of goods, the economic system may fall into recession $[3,4,5,6,7]$. At the macroeconomic level, it is accompanied by a devaluation of the national currency, inflation, a fall in assets prices. The phenomenon was called the breakdown of the exchange mechanism. It is possible to reveal it in advance from the statistical information on the structure of production, outputs, foreign economic relations.

There are many factors destabilizing economy, however, all they are only a trigger to destruct the exchange mechanism. The hidden reason of the exchange mechanism breakdown is the quality of equilibrium state that can be determined by the structural characteristics of the economy $[3,4,5,6,7]$.

How does monetary policy affect the recession in the economy? First, we study the influence of monetary policy on the exchange rate in nonlinear regression models and establish the equation of money circulation.

The description of the national currency / dollar exchange rate by a random process satisfying the difference stochastic equation confirms that the logarithm of the exchange rate is a random walk without a drift. On this basis, the equation of money circulation in 2015 - 2017 was found. In this paper, basing on the fact that the currency exchange rate of the country relative to the USA dollar is an indicator of the economy equilibrium with its environment we formulate the canonical equation of money circulation which is a functional dependence between the amount of money in the economy, GDP and the refinance rate of the Central Bank of the state. Starting from this, we formulate the definition of the permanent economy development and its stability. The deviation from it means the different degree of approaching the economy to the recession state. These notions we are applied to the investigation of the economies of Germany, France, Italy. After that we investigate the question of adequacy of the currency exchange rate to the factors that determine it. We formulate the dynamic stochastic model for the evolution of the currency exchange and inflation rates as unobservable random process the estimate of which we obtain by the Kalman filter method ${ }^{[8,9]}$.

\section{Exchange rate model}

Here we present the heuristic arguments for the equation managing the money circulation. Let us obtain the discrete evolution of the national currency / dollar exchange rate. Suppose that

$p_{t}$ and $p_{t}^{*}$ are the logarithms of consumer price indices at the time moment $t$, then up to the constant depending only on the choice of the base year prices, $p_{t}-p_{t}^{*}$ is a logarithm of the national currency / dollar exchange rate due to the monetary approach of the exchange rate formation. To obtain the equation managing the exchange rate, let us take the money circulation equations for two countries in the form

$$
\begin{aligned}
& m_{t}=p_{t}+k y_{t}-\lambda r_{t}, \\
& m_{t}^{*}=p_{t}^{*}+k^{*} y_{t}^{*}-\lambda^{*} r_{t}^{*},
\end{aligned}
$$

where $m_{t}, y_{t}, r_{t}$ are the logarithms of the money supply, the gross domestic product and the refinance rate of the Central Bank at the moment 
$t$, and $k, \lambda, k^{*}, \lambda^{*}$ are some constants.

Equation (2) refers to the foreign economy. Using that the exchange rate

$$
s_{t}=p_{t}-p_{t}^{*}+a,
$$

and the formulae (1), (2), we have $s_{t}=a+m_{t}-m_{t}^{*}-\left(k y_{t}-k^{*} y_{t}^{*}\right)+\lambda r_{t}-\lambda^{*} r_{t}^{*}$

Equation (4) requires many assumptions. Among them, the flexibility of prices in both economies. It bonds is difficult to argument for neglecting of the market for goods, labor, foreign economic relations. We simplify the model assuming that $k=k^{*}, \lambda=\lambda^{*}$. From (4)

we obtain $s_{t}=a+m_{t}-m_{t}^{*}-k\left(y_{t}-y_{t}{ }^{*}\right)$

$+\lambda\left(r_{t}-r_{t}^{*}\right)$.

The coefficients entering equation (5) are be determined. Simple relation between the exchange rate, the consumer price indices, the gross domestic products, the money supply entering in money circulation equation (5) can not hold deterministically in view of restrictions for the monetary model to be valid. Just the monetary circulation equation itself is not known. Further, we assume that the deviation of the left side of (5) from the right one is a random process. Therefore, suppose that the discrete random process $\varsigma_{k+1, i}, i=\overline{-p, 0}$, and $k$ factors

$$
X_{i}=\left\{x_{j i}\right\}_{j=0}^{k}, i=\overline{0, n},
$$

$X_{0}=\left\{x_{j 0}\right\}_{j=1}^{k}, x_{j 0}=1, j=\overline{1, k}$, are such that

$$
\sum_{s=0}^{p} a_{s} \varsigma_{k+1, i-s}-f_{i}\left(X_{0}, X_{1}, \ldots, X_{k}\right)=\varepsilon_{i}, \quad i=\overline{1, n},
$$

where $a_{0}=1$, the random values $\varsigma_{k+1,-p}, \ldots$, $\varsigma_{k+1,0}$ are known, the random values $\varepsilon_{i}, i=\overline{1, n}$, are independent with zero mean and dispersion $\sigma^{2}$, also, $\varsigma_{k+1,-p}, \ldots, \varsigma_{k+1,0}$ do not depend on $\varepsilon_{i}$, $i=\overline{1, n}$, the functions $f_{i}\left(X_{0}, X_{1}, \ldots, X_{k}\right), i=\overline{1, n}$, are nonlinear functions of the factors. The most important case is when
$f_{i}\left(X_{0}, X_{1}, \ldots, X_{k}\right)=\sum_{j=0}^{k} b_{j} x_{j i}, \quad i=\overline{1, n}$,

and the equalities (6) become

$\varsigma_{k+1, i}-\sum_{j=0}^{k} b_{j} x_{j i}=\varepsilon_{i}, \quad i=\overline{1, n}$.

Therefore, we further assume that the set of random variables $\varsigma_{k+1, i}, i=\overline{1, n}$, are independent and have the joint normal distribution with mean $E \varsigma_{k+1, i}=\sum_{j=0}^{k} b_{j} x_{j i}$ and dispersion $\sigma^{2}$. It follows

from (7) that the best forecast of a random process $\varsigma_{k+1, i}, i=\overline{1, n}$, is its mean. To write the maximum likelihood estimate for the vector $b=\left\{b_{0}, b_{1}, \ldots, b_{k}\right\}$ and the determination coefficient which is the correlation of the process and its prediction in a convenient way we introduce the matrix $X$, whose columns are the vectors $X_{i}, i=\overline{0, k}, \quad$ where $\quad X_{i}=\left\{x_{i j}\right\}_{j=1}^{n}, \quad i=\overline{1, k}$, $X_{0}=\left\{e_{j}\right\}_{j=1}^{n}, e_{j}=1, j=\overline{1, n}$.

Then this matrix can be represented as

$$
X=\left(\begin{array}{c}
1, x_{11}, \ldots, x_{k 1} \\
\ldots \ldots \ldots \ldots \ldots \ldots . . . \\
1, x_{1 n}, \ldots, x_{k n}
\end{array}\right),
$$

and the set of equations (7) as

$$
\varsigma_{k+1}=X b+\varepsilon,
$$

where $\varsigma_{k+1}=\left\{\varsigma_{k+1, i}\right\}_{i=1}^{n}, \quad \varepsilon=\left\{\varepsilon_{i}\right\}_{i=1}^{n}$ are column vectors containing corresponding elements $\varsigma_{k+1, i}$ and $\varepsilon_{i}$. Let the matrix $X$ rank be $k+1$. Denote $A=X^{T} X$, it is symmetrical matrix having inverse one and the maximum likelihood estimate (MLE) for the coefficients of the column vector $b=\left\{b_{0}, b_{1}, \ldots, b_{k}\right\}$ is unbiased and can be given in the form

$\bar{b}=A^{-1} X^{T} \varsigma_{k+1}$.

The quality of the regression model is determined by the sample multiple correlation coefficient between the sample and the forecast 
$R_{n-1}=\frac{\sum_{i=1}^{n}\left(x_{k+1, i}-\overline{x_{k+1}}\right)\left(x_{k+1, i}^{1}-\overline{x_{k+1}^{1}}\right)}{\sqrt{\sum_{i=1}^{n}\left(x_{k+1, i}-\overline{x_{k+1}}\right)^{2} \sum_{i=1}^{n}\left(x_{k+1, i}^{1}-\overline{x_{k+1}^{1}}\right)^{2}}}$,

where $x_{k+1}^{1}=X \bar{b}=\left\{x_{k+1, i}^{1}\right\}_{i=1}^{n}$, and $\overline{x_{k+1}}=\frac{\sum_{i=1}^{n} x_{k+1, i}}{n}$ $\overline{x_{k+1}^{1}}=\frac{\sum_{i=1}^{n} x_{k+1, i}^{1}}{n}$.

It is easy to show that for $R_{n-1}^{2}$ the representation

$$
R_{n-1}^{2}=\frac{\sum_{i=1}^{n}\left(x_{k+1, i}^{1}-\overline{x_{k+1}^{1}}\right)^{2}}{\sum_{i=1}^{n}\left(x_{k+1, i}-\overline{x_{r+1}}\right)^{2}}
$$

is valid. $R_{n-1}^{2}$ is called determination coefficient. The closer it is to unity, the better the quality of regression is. To calculate it, it is convenient to write the determination coefficient in the form

$$
R_{n-1}^{2}=\frac{<x_{k+1}-\overline{x_{k+1}}, X_{1} A_{1}^{-1} X_{1}^{T}\left(x_{k+1}-\overline{x_{k+1}}\right)>}{<x_{k+1}-\overline{x_{k+1}}, x_{k+1}-\overline{x_{k+1}}>},
$$

where

$$
X_{1}=\left(\begin{array}{l}
x_{11}^{1}, \ldots, x_{k 1}^{1} \\
\ldots \ldots \ldots \ldots \ldots . . . \\
x_{1 n}^{1}, \ldots, x_{k n}^{1}
\end{array}\right) \text {, }
$$

$x_{j i}^{1}=x_{j i}-\frac{\sum_{i=1}^{n} x_{j i}}{n}, A_{1}=X_{1}^{T} X_{1}, x_{k+1}-\overline{x_{k+1}}=\left\{x_{k+1, i}-\right.$ $\left.\frac{\sum_{i=1}^{n} x_{k+1, i}}{n}\right\}_{i=1}^{n}$,

and $<a, b>$ is scalar product of the vectors $a$ and $b$. The estimation of maximum likelihood for dispersion $\sigma^{2}$ is

$$
\sigma^{2}=\frac{<x_{k+1}-\bar{b}, x_{k+1}-\bar{b}>}{n} .
$$

One can judge the quality of the factors on the basis of the Snedekor-Fisher statistics

$$
\eta_{n-k-1, k+1}=
$$

$$
\frac{<\varepsilon,\left(I-X A^{-1} X^{T}\right) \varepsilon>}{<\varepsilon, X A^{-1} X^{T} \varepsilon>} \frac{(k+1)}{(n-k-1)},
$$

where $\varepsilon=\left\{\varepsilon_{i}\right\}_{i=1}^{n}$, and the random values $\varepsilon_{i}=\frac{\varsigma_{k+1, i}-E \varsigma_{k+1, i}}{\sigma}, i=\overline{1, n}$, have the normal distribution $N(0,1)$ with zero mean and unit dispersion and are reciprocally independent. $E \varsigma_{k+1, i}$ is mean value of the random value $\varsigma_{k+1, i}$.

\section{Canonical money circulation equation}

The equation of money circulation in the economy can serve as the additional instrument to analyse the approaching to the recession state by the economy. But there are no the mathematical methods to obtain the relationship between the amount of money in the economy, gross domestic product (GDP) and the refinance rate of the Central bank. As it was shown by one of the author in the paper [3] if the demand on a certain group of goods is equal zero then GDP decreases and the national currency devaluates. The depth of the decreasing of GDP depends on the quality of the equilibrium state, that is, on the degeneracy multiplicity of the economy equilibrium state.

The reaction of the Central bank on a such economic equilibrium state may be various: it decreases the refinance rate to increase the amount of money in the economy if the aim is to reform the economy sector where the demand on a certain group of goods is sufficiently small, or it increases the refinance rate to decrease the amount of money in the economy to avoid the inflation of prices. All this depends on the assessment of the depth of recession in demand. We proceed from the assumption that the integral indicator of the equilibrium of the economy system with its environment is the exchange rate of the national currency relative to the USA dollar. Taking into account this fact and the monetary approach to the currency exchange rate formation we formulate the stochastic equation for the forcast of the currency exchange rate relative to the USA dollar. The best forcast of the currency exchange 
rate relative to the USA dollar is used to obtain the money circulation equation in the considered period. This enables us to formulate the conditions of the sustainable economy development. Using the statistics for Germany, France, Italy [10-21] for each of them the money circulation equation is established and on this basis the classification of the monetary policy for all of them is given. The economy whose the money circulation equation satisfies the conditions of the sustainable economy development can affect the amount of money in the economy changing the refinance rate. If the degeneracy multiplicity of the economy equilibrium state is not high then Central Bank can affect the amount of money in the economy. In this section, using the statistics of 2015-2017 [10-21] for Germany, France, Italy, we establish a stochastic difference equation that national currency / dollar exchange rate satisfies. Since the quarterly statistical data 2015-2017 are known, in our case we use the following notation.

The dependent variable $Y_{i}, i=\overline{1, n}$, describes national currency / dollar exchange rate evolution. Introduce the vector $Y=\left\{Y_{i}\right\}_{i=1}^{n}$. Let $X_{0}=\left\{e_{i}\right\}_{i=1}^{n}, e_{i}=1, i=\overline{1, n}$, be a unit vectorcolumn and let $G_{1}=\left\{G_{i}^{1}\right\}_{i=1}^{n}, \quad G_{2}=\left\{G_{i}^{2}\right\}_{i=1}^{n}$ be vectors-columns of gross domestic products for the considered country and USA, respectively, and $M_{1}=\left\{M_{i}^{1}\right\}_{i=1}^{n}, \quad M_{2}=\left\{M_{i}^{2}\right\}_{i=1}^{n}$ be money supply vectors for the considered country and USA. Let $R_{1}=\left\{R_{i}^{1}\right\}_{i=1}^{n}, \quad R_{2}=\left\{R_{i}^{2}\right\}_{i=1}^{n}$ be refinance rates of the Central Bank of the considered country and the USA Federal Reserve System, correspondingly. Introduce the vectors

$$
\begin{gathered}
\left.m_{1}=\log \left(M_{1}\right)=\left\{\log M_{i}^{1}\right\}_{i=1}^{n}=\left\{m_{i}^{1}\right)\right\}_{i=1}^{n}, \\
\left.m_{2}=\log \left(Y^{*} M_{2}\right)=\left\{\log \left(Y_{i} M_{i}^{2}\right)\right\}_{i=1}^{n}=\left\{m_{i}^{2}\right)\right\}_{i=1}^{n}, \\
r_{1}=\log \left(R_{1}\right)=\left\{\log R_{i}^{1}\right\}_{i=1}^{n}=\left\{r_{i}^{1}\right\}_{i=1}^{n}, \\
r_{2}=\log \left(R_{2}\right)=\left\{\log R_{i}^{2}\right\}_{i=1}^{n}=\left\{r_{i}^{2}\right\}_{i=1}^{n}, \\
g_{1}=\log \left(G_{1}\right)=\left\{\log G_{i}^{1}\right\}_{i=1}^{n}==\left\{g_{i}^{1}\right\}_{i=1}^{n}
\end{gathered}
$$

$$
\begin{gathered}
g_{2}=\log \left(Y^{*} G_{2}\right)=\left\{\log \left(Y_{i} G_{i}^{2}\right)\right\}_{i=1}^{n}=\left\{g_{i}^{2}\right\}_{i=1}^{n}, \\
y=\log (Y)=\left\{\log Y_{i}\right\}_{i=1}^{n}=\left\{y_{i}\right\}_{i=1}^{n} .
\end{gathered}
$$

Let the vector $\left\{y_{i}\right\}_{i=1}^{n}$ be a random process satisfying the stochastic equation

$$
\begin{aligned}
& y_{i}=b_{0}+b_{1}\left(m_{i}^{1}-m_{i}^{2}\right)+b_{2}\left(g_{i}^{1}-g_{i}^{2}\right)+b_{3}\left(r_{i}^{1}-r_{i}^{2}\right)+\varepsilon_{i}, \\
& i=\overline{1, n}, \quad \text { (17) }
\end{aligned}
$$

where $\varepsilon_{i}$ are independent random values distributed by the law $N(0, \sigma)$. Introduce the vector-columns $X_{1}=m_{1}-m_{2}, X_{2}=g_{1}-g_{2}, X_{3}=$ $r_{1}-r_{2}$, where $X_{i}=\left\{x_{i j}\right\}_{j=1}^{n}, i=\overline{0,3}$. We have the problem to astimate the parameters as in the problem (7) with $b_{1}=1$. Let $b_{0}, b_{2}, b_{3}$ be such parameters. From the equation (24) we obtain the best forcast for the currency exchange rate

$Y_{i}=e^{b_{0}} \frac{M_{i}^{1}}{M_{i}^{2} Y_{i}} \frac{\left[G_{i}^{1}\right]^{b_{2}}}{\left[G_{i}^{2} Y_{i}\right]^{b_{2}}} \frac{\left[R_{i}^{1}\right]^{b_{3}}}{\left[R_{i}^{2}\right]^{b_{3}}}, i=\overline{1, n}$.

From the equation (18) we obtain the equality

$$
M_{i}^{1}=e^{-b_{0}}\left[Y_{i}\right]^{2} M_{i}^{2}\left[G_{i}^{2} Y_{i}\right]^{b_{2}}\left[R_{i}^{2}\right]^{b_{3}}\left[G_{i}^{1}\right]^{-b_{2}}\left[R_{i}^{1}\right]^{-b_{3}}
$$

$i=\overline{1, n}$.

Let us introduce the denotations

$F_{i}=e^{-b_{0}}\left[Y_{i}\right]^{2} M_{i}^{2}\left[G_{i}^{2} Y_{i}\right]^{b_{2}}\left[R_{i}^{2}\right]^{b_{3}}, f_{i}=\log F_{i}$,

$i=\overline{1, n}$, and let us consider the problem

$$
\min \sum_{i=1}^{n}\left(f_{i}-a_{0}-a_{2} g_{i}^{1}-a_{3} r_{i}^{1}\right)^{2} \text {. }
$$

Then the equation (19) can be represented in the canonical form

$$
M_{i}^{1}=e^{a_{0}}\left[G_{i}^{1}\right]^{a_{2}-b_{2}}\left[R_{i}^{1}\right]^{a_{3}-b_{3}}, i=\overline{1, n},
$$

where $a_{0}, a_{2}, a_{3}$ is a solution of the problem (20).

We call the functional dependence (21) between the variables $M_{i}^{1}, G_{i}^{1}, R_{i}^{1}$ the canonical equation of money circulation in the $i$-th period, $i=\overline{1, n}$.

Definition 1. We say that an economy within the period of functioning is in the state of the JME: https://escipub.com/journal-of-modern-economy/ 
sustainable economy development if the canonical equation of the money circulation satisfies the conditions: $L_{2}=a_{2}-b_{2}>0$, $L_{3}=a_{3}-b_{3}<0$.

Below we analyse the economy state for three countries on the basis of their statistics during 2015 -2017 years [9-21].

The canonical equation of money circulation for the Germany economy satisfies the criterion of the sustainable economy development since $L_{2}=1,937858 \quad L_{3}=-0,098206$. The standard deviation equals $\sigma=0.086$. Really, for 2015 2017 years [9-21] in the German economy we observe the oscillation of GDP. During these years the Central Bank of Germany trying to stabilize the economy was changing the refinance rate trying to increase the demand on the produced goods in the economy. The amount of money in the economy was permanently increased and these actions of the Central Bank affected the state of the economy for $2015-2017$ years [10-21]. If the velocity of money circulation $V_{1}$, then

$V_{1}=\frac{G_{1}}{M_{1}}$.

The velocity of money circulation fell for the Germany economy for ten quarter and after that it began to increase. On Figure 1 we present the functional dependence of GDP, the money supply, and the canonical money circulation equation in time for the German economy and on the Figure 2 the velocity of money circulation during 2015-2017 years.

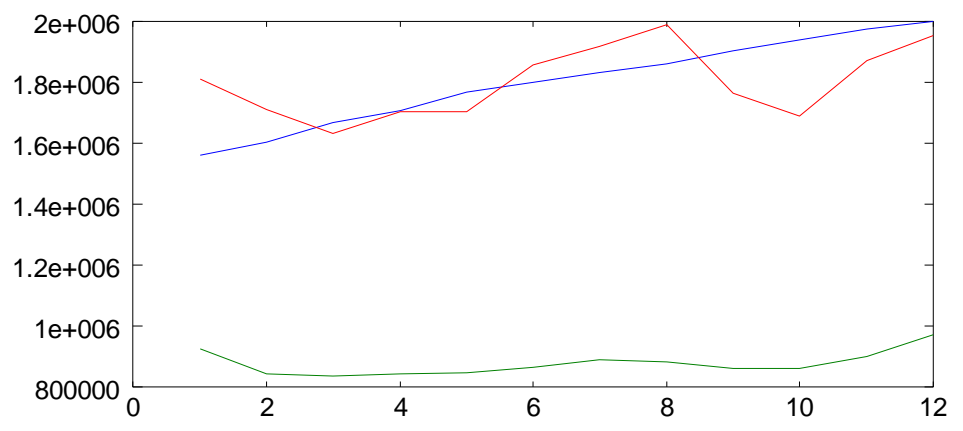

Figure 1. Canonical equation of money circulation for Germany economy during $2015-2017$ years.

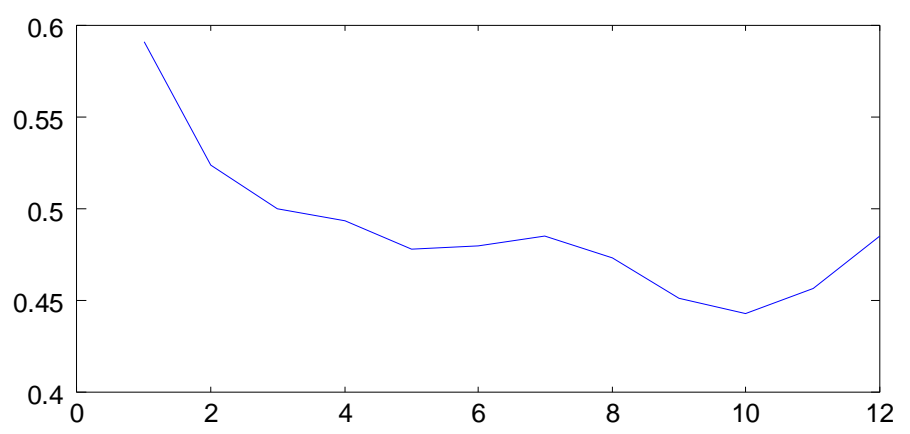

Figure 2. The velocity of money circulation for Germany economy during $2015-2017$ years.

The canonical equation of money circulation for the France economy satisfies the criterion of the sustainable economy development since $L_{2}=1.930125, \quad L_{3}=-0.051910$, the standard deviation equals $\sigma=0.078$. In the considered period for the France economy we observe the slow oscillating of the GDP. The amount of money in the economy of France was increased in this period. The refinance rate of the Central Bank of France in the considered period has oscillating character. We observe the adequate reaction of the Central Bank on the state of the economy for 2015 -2017 years.

At the beginning of the considered period the 
Nicholas S. Gonchar and Olena P. Dovzhyk, JME 2022,5:14

velocity of money circulation was increasing and at the end of the period it began to increase.

The functional dependence of GDP, the money supply, and the canonical money circulation for the France economy in time and the velocity of money circulation is presented below on Figures 3 and 4 , respectively.

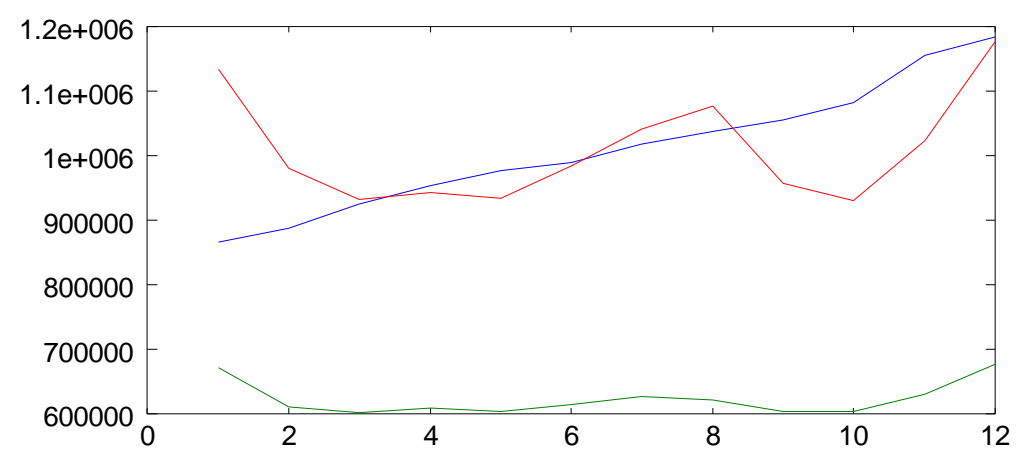

Figure 3. Canonical money circulation equation for France economy during $2015-2017$ years.

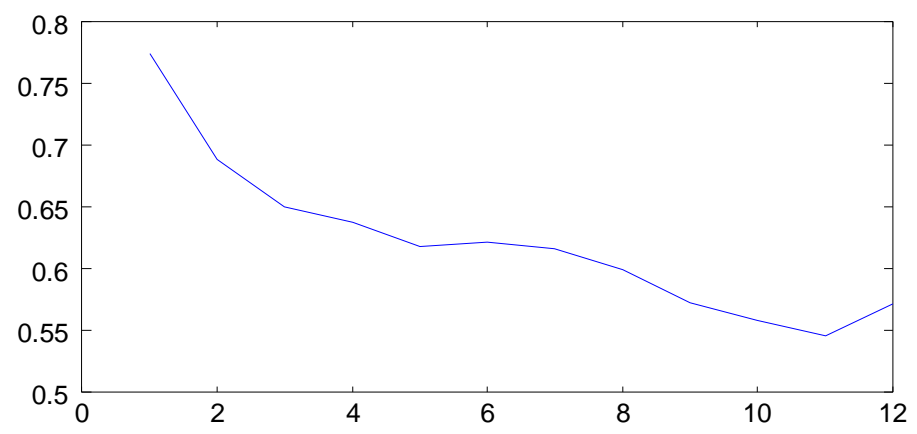

Figure 4. The velocity of money circulation for France economy during $2015-2017$ years.

The canonical equation of money circulation for the Italy economy satisfies the criterion of the sustainable economy development with $L_{2}=0.1362976, \quad L_{3}=-0.069739$, the standard deviation equals $\sigma=0.069$. The values of $L_{2}$, $L_{3}$ are very small. This indicates that the economy of Italy was close to the unstable state. In the considered period we observe that GDP has slowly oscillating character. The amount of money in the economy was increasing for all the time. In the considered period the refinance rate has also oscillating character to stabilize economy.

In the considered period the velocity of money circulation was decreasing and after that it began to increase.

Below on Figure 5, we present the functional dependence of GDP, the money supply and the canonical money circulation equation in time for the Italy economy and the velocity of money circulation on Figure 6 for $2015-2017$ of years.

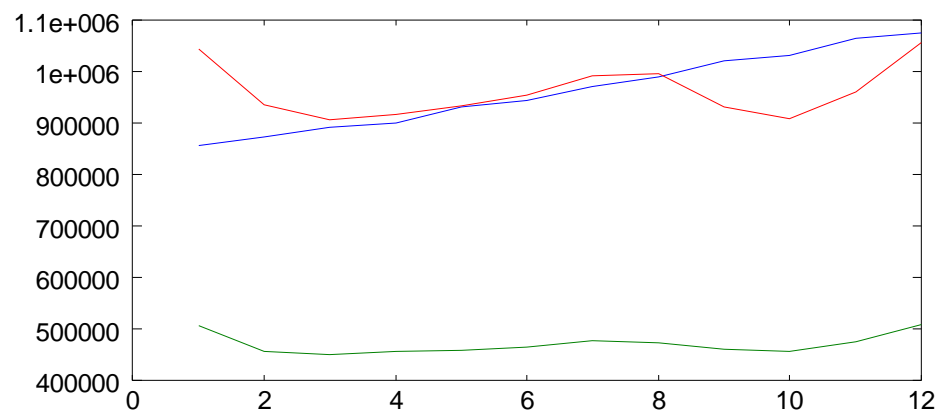

Figure 5. Canonical money circulation equation for Italy economy during $2015-2017$ years. 


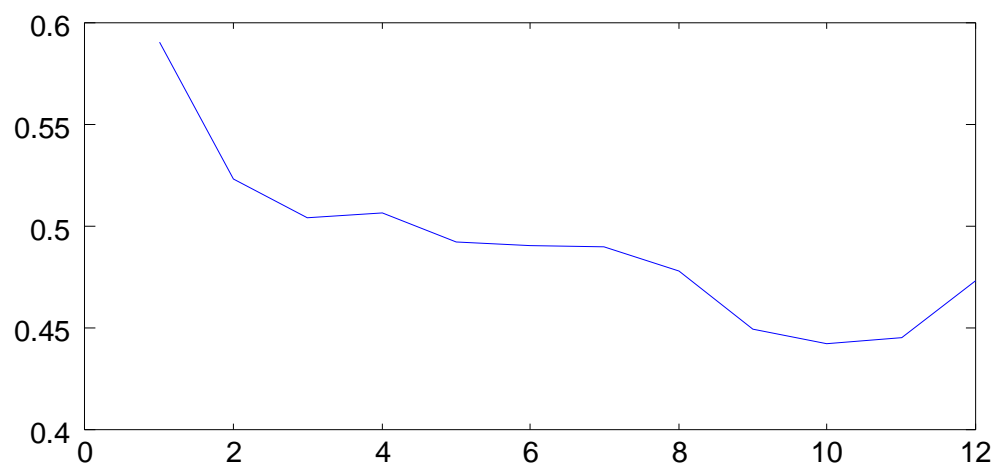

Figure 6. The velocity of money circulation for Italy economy during $2015-2017$ years.

\section{Stability of the state of the economy equilibrium.}

In this section we give a specific definition of the stability of the state of economic equilibrium.

Its essence is that the past exchange rate does not have a significant effect on its future values, which will significantly change the state of economic equilibrium.

The obtained estimates of parameters in the equation (17) allow us to predict the exchange rate. We formulate the above definition of the stability of the state of the economy in an analytical form.

Let the random process $y$ satisfy the stochastic equation

$y_{i}=b_{0}+b_{1}\left(m_{i}^{1}-m_{i}^{2}\right)+b_{2}\left(g_{i}^{1}-g_{i}^{2}\right)+b_{3}\left(r_{i}^{1}-r_{i}^{2}\right)$

$+b_{4} y_{i-1}+\varepsilon_{i}, \quad i=\overline{1, n}$,

where $\varepsilon_{i}$ are independent random values distributed by the law $N(0, \sigma)$, and $y_{0}$ is known number.

From the equation (23) we obtain the best forcast for the currency exchange rate $Y_{i}=e^{b_{0}} \frac{M_{i}^{1}}{M_{i}^{2} Y_{i}} \frac{\left[G_{i}^{1}\right]^{b_{2}}}{\left[G_{i}^{2} Y_{i}\right]^{b_{2}}} \frac{\left[R_{i}^{1}\right]^{b_{3}}}{\left[R_{i}^{2}\right]^{b_{3}}}\left[Y_{i-1}\right]^{b_{4}} \quad, \quad i=\overline{1, n}$.

From the equation (24) we obtain the equality $M_{i}^{1}=e^{-b_{0}}\left[Y_{i}\right]^{2} M_{i}^{2}\left[G_{i}^{2} Y_{i}\right]^{b_{2}}\left[R_{i}^{2}\right]^{b_{3}}\left[Y_{i-1}\right]^{-b_{4}} \times$

$\left[G_{i}^{1}\right]^{-b_{2}}\left[R_{i}^{1}\right]^{-b_{3}}, \quad i=\overline{1, n}$.

$$
\begin{aligned}
F_{i} & =e^{-b_{0}}\left[Y_{i}\right]^{2} M_{i}^{2}\left[G_{i}^{2} Y_{i}\right]^{b_{2}}\left[R_{i}^{2}\right]^{b_{3}}\left[Y_{i-1}\right]^{-b_{4}}, f_{i}=\log F_{i}, \\
i & =\overline{1, n} .
\end{aligned}
$$

And let us consider the problem

$$
\min \sum_{i=1}^{n}\left(f_{i}-a_{0}-a_{2} g_{i}^{1}-a_{3} r_{i}^{1}\right)^{2} \text {. }
$$

Then the equation (26) can be represented in the canonical form

$$
M_{i}^{1}=e^{a_{0}}\left[G_{i}^{1}\right]^{a_{2}-b_{2}}\left[R_{i}^{1}\right]^{a_{3}-b_{3}} .
$$

Definition 2. We say that an economy in its period of functioning is in the stable state of the equilibrium if the canonical equation of the money circulation (27) satisfies the conditions: $L_{2}=a_{2}-b_{2}>0$,

$L_{3}=a_{3}-b_{3}<0$, for the value of the number $y_{0}$ that is in the neighbourhood of the number $y_{1}$, which is the first component of the vector $y$.

As earlier, introduce the vectors-columns $X_{1}=m_{1}-m_{2} \quad, \quad X_{2}=g_{1}-g_{2}, X_{3}=r_{1}-r_{2} \quad$, $X_{4}=\left\{y_{i-1}\right\}_{i=1}^{n-1}$, where $X_{i}=\left\{x_{i j}\right\}_{j=1}^{n}, i=\overline{0,4}$. We have the parameters estimate problem as in (14) with $b_{1}=1$. In this section we analyze the economy of three countries from the point of view how they was close to the recession state. We are interested in the question of stability of economy development.

For the Germany economy the least squares estimation gives $L_{2}=2.052434, L_{3}=-0.078787$. The standard deviation estimate $\sigma=0.050808$. .

Let us introduce the denotations 
From this we conclude that the Germany economy was in the stable state with $y_{0} \leq 0.11$. For the France economy the least squares estimation gives $L_{2}=2.678584, L_{3}=-0.015380$ .The standard deviation estimate $\sigma=0.076173$. From this we conclude that the France economy was in the stable state with $y_{0} \leq 0.14$. For the Italy economy the least squares estimation gives $L_{2}=1.766768, L_{3}=-0.017005$. The standard deviation estimate $\sigma=0.068$. From this we conclude that the Italy economy was in the stable state with $y_{0} \leq 0.11$.

\section{Dependence of the exchange rate on the internal factors}

In this and next sections we give the justification of suppositions made in the previous sections. We clarify whether the exchange rate play the determining role in establishing equilibrium between an open economy and its environment. In this section we clear up the internal factors determining the exchange rate and in the next one we propose the verification mechanism of adequacy inflation and exchange rates to the determining factors. For this purpose we assume that the unobserved random process inflation and exchange rates satisfies the stochastic equation determined by the internal factors. To estimate this unobserved process we use Kalman filtrer method.

Now we'll find out the effect of inflation, the budget deficit, the level of energy prices, current account balance, trade balance, and money supply on the exchange rate. As before, we assume the exchange rate to be a random process satisfying the set of equations (6). More detailed, the exchange rate is influenced by the factors $X_{i}=\left\{x_{i j}\right\}_{j=1}^{n}, i=\overline{0,5}$, where

$X_{0}=\left\{e_{i}\right\}_{i=1}^{n}, e_{i}=1, i=\overline{1, n}$, is an unit vectorcolumn, $X_{1}=\left\{x_{1 j}\right\}_{j=1}^{n}$ is an inflation level, $X_{2}=\left\{x_{2 j}\right\}_{j=1}^{n}$ is a budget government deficit,
$X_{3}=\left\{x_{3 j}\right\}_{j=1}^{n}$ is an energy carriers' price, $X_{4}=\left\{x_{4 j}\right\}_{j=1}^{n}$ is a current account balance, $X_{5}=\left\{x_{5 j}\right\}_{j=1}^{n}$ is a trade balance, $X_{6}=\left\{x_{6 j}\right\}_{j=1}^{n}$ is a money supply. With $y=\log (Y)=\left\{\log Y_{i}\right\}_{i=1}^{n}$ $=\left\{y_{i}\right\}_{i=1}^{n}$ we'll assume the random process $y$ satisfy

the set of equations

$$
\begin{aligned}
& y_{i}=b_{0}+b_{1} x_{1 i}+b_{2} x_{2 i}+b_{3} x_{3 i}+b_{4} x_{4 i}+b_{5} x_{5 i} \\
& +b_{6} x_{6 i}+b_{7} y_{i-1}+\varepsilon_{i}, i=\overline{1, n},
\end{aligned}
$$

where $\varepsilon_{i}, i=\overline{1, n}$, is the set of independent random values distributed by the normal law $N(0, \sigma)$ and $y_{0}$ is a fixed number. For the Germany economy maximum likelihood estimate for the vector $B=\left\{b_{i}\right\}_{i=0}^{6}$ gives the result $b_{0}=-2.3 \cdot 10^{-2}, b_{1}=-1.6 \cdot 10^{-2}, b_{2}=-2.8 \cdot 10^{-13}$, $b_{3}=4.1 \cdot 10^{-3}, \quad b_{4}=1.1 \cdot 10^{-12}, \quad b_{5}=1.1 \cdot 10^{-12}$, $b_{6}=8.8 \cdot 10^{-13}, b_{7}=-6.5 \cdot 10^{-1}$ for $y_{0} \leq 0.1$. The determination coefficient $R_{11}^{2}=0.71$, and standard deviation estimate $\sigma=0.021170$.

For the France economy maximum likelihood estimate for the vector $B=\left\{b_{i}\right\}_{i=0}^{6}$ gives the result $b_{0}=1.5 \cdot 10^{-1}, b_{1}=1.5 \cdot 10^{-4}, b_{2}=3.3 \cdot 10^{-12}$, $b_{3}=-9.8 \cdot 10^{-4}, b_{4}=4.1 \cdot 10^{-11}, b_{5}=-3 \cdot 10^{-11}$, $b_{6}=3.7 \cdot 10^{-14}, b_{7}=2.5 \cdot 10^{-1}$ for $y_{0} \leq 0.1$. The determination coefficient $R_{11}^{2}=0.73906$, and the standard deviation estimate $\sigma=0.019830$.

The maximum likelihood estimate for the vector $B=\left\{b_{i}\right\}_{i=0}^{6}$ for the Italy economy gives the result $b_{0}=1.55 \cdot 10^{-1}, b_{1}=-6.3 \cdot 10^{-3}, b_{2}=-2.1 \cdot 10^{-12}$ $b_{3}=1.8 \cdot 10^{-3} \quad, \quad b_{4}=2.1 \cdot 10^{-11} \quad b_{5}=-1.8 \cdot 10^{-11}$, $b_{6}=5.3 \cdot 10^{-13}, b_{7}=-3.2 \cdot 10^{-1}$ for $y_{0} \leq 0.1$. The determination coefficient $R_{11}^{2}=0.74863$, and the standard deviation estimate $\sigma=0.019462$. 
The latter indicates a very close relationship of the exchange rate with inflation, the budget government deficit, the level of energy prices, current account balance, trade balance, and money supply.

\section{The adequacy of the exchange and the inflation rates to determining factors}

In the previous section the question of the correspondence of the currency exchange to the determining factors is studied. Found relation is sufficiently close. Below we propose a new method to establish the adequacy of the currency exchange rate to the determining factors. Formation of the exchange and inflation rates in non-competitive economies may occur inadequately to the economically determining factors. This is due to the influence of monopoly on economic processes and the deformed taxation system, which contribute to inflationary processes and inadequate changes in the national currency / dollar rate. Using the introduced concept of the exchange and inflation rates adequacy, we find out their relevance to the determining factors.

We believe that the national currency / dollar rate and the inflation rate are determined by the factors: energy prices, government budget deficit, current balance of payments, trade balance, money supply.

The complexity of the problem lies in the fact that there is no unambiguous stochastic dynamic evolution of the economy. The main assumption is that the national currency / dollar rate and the rate of inflation are determined mainly by a certain set of factors and is an unobservable process whose estimate should be found.

Formulation of the problem. The evolution of factors $Y_{i}, i=\overline{1, N}$, is given that can affect the inflation and the exchange rates, as well as the evolution of the inflation rate and the exchange rate of national currency / dollar $x_{i}, i=\overline{1, N}$, is also given, where the dimensionality of the vector of factors is $n$, and the dimensionality of the vector $x_{i}$ is equal to 2 . One must clarify the adequacy of the influence of factors on the inflation and exchange rates. Below we assume that $N=5$. Every vector $N_{i}, i=\overline{1,5}$, has dimension 12. These are such vectors: budget deficit, the level of energy prices, current account balance, trade balance and money supply.

We'll solve the problem by constructing unobservable random process $\bar{x}_{k}$ being adequate inflation rate and exchange rate within $k$-th period that evolves by the law

$\bar{x}_{k+1}=F_{k, k+1} \bar{x}_{k}+w_{k}, \quad k=0, N-1$,

$Y_{k+1}=H_{k} \bar{x}_{k}+v_{k}, \quad k=\overline{0, N-1}$,

considering $w_{k}$ and $v_{k}$ to be Gauss white noises, i.e., $E w_{k}^{i} v_{s}^{j}=0$, where

$$
E w_{k}^{i} v_{s}^{j}=\delta_{k s} \delta_{i j} a^{i}, \quad a^{i}>0, i=1,2
$$

$E v_{k}^{i} v_{s}^{j}=\delta_{k s} \delta_{i j} b^{i}, \quad b^{i}>0, i=\overline{1, N}$,

with zero mean $E w_{k}=0, E v_{k}=0 . \quad F_{k, k+1}=\mathrm{E}$ is unit $2 \times 2$ matrix.

We determine the matrix $H_{k}$ from the condition of minimum for the functional

$$
\begin{aligned}
& \min \sum_{i=1}^{n}\left\{\left[y_{i}^{k}-h_{i 1}^{k} x_{1}^{k}-h_{i 2}^{k} x_{2}^{k}\right]^{2}\right. \\
& \left.+\left[y_{i}^{k+1}-h_{i 1}^{k} x_{1}^{k+1}-h_{i 2}^{k} x_{2}^{k+1}\right]^{2}\right\}
\end{aligned}
$$

where $H_{k}=\left|h_{i 1}^{k}, h_{i 2}^{k}\right|_{i=1}^{n}, Y_{i}^{k}=\left\{y_{i}^{k}\right\}_{i=1}^{n}, k=1, N$.

At the beginning time moment

$\hat{x}_{0}=E \bar{x}_{0}$,

$P_{0}=E\left(\bar{x}_{0}-E \bar{x}_{0}\right)\left(\bar{x}_{0}-E \bar{x}_{0}\right)^{T}$.

We describe the evolution of the state estimate by the formula $[7,8]$

$\hat{x}_{k}^{-}=F_{k, k-1} \hat{x}_{k-1}^{-}$.

Errors matrix within the time period $[k-1, k]$ is given by the expression

$P_{k}^{-}=F_{k, k-1} P_{k-1} F_{k, k-1}^{T}+Q_{k-1}$.

JME: https://escipub.com/journal-of-modern-economy/ 
Kalman

$G_{k}=P_{k}^{-} H_{k}^{T}\left[H_{k} P_{k}^{-} H_{k}^{T}+R_{k}\right]^{-1}$

and $\quad \hat{x}_{k}=\hat{x}_{k}^{-}+G_{k}\left(Y_{k+1}-H_{k} \hat{x}_{k}^{-}\right)$.

Updated bug matrix is

$$
P_{k}=\left(E-G_{k} H_{k}\right) P_{k}^{-} \text {. }
$$

We suppose that $F_{k, k+1}=\mathrm{E}$, where $\mathrm{E}$ is unit $2 \times 2$ matrix. matrix In the Table1, we show the quarterly change in the Germany inflation and euro / USD rates for 2015 - 2017 years. The forcast of the euro exchange rate relative to the USA dollar being adequate to the determining factors oscillates in correspondence with the current account balance that was positive for the considered years.This forcast of the euro exchange and inflation rates is closely correlated with the observable data.

Table 1. Forcast of inflation and exchange rates for Germany economy.

\begin{tabular}{|c|c|c|c|}
\hline \multicolumn{2}{|c|}{ Statistical data } & \multicolumn{2}{c|}{ Forecast } \\
\hline 0.50 & 1.21 & & \\
\hline-0.05 & 1.08 & & \\
\hline 0.97 & 1.12 & -0.10 & 1.06 \\
\hline 0.73 & 1.12 & 1.14 & 1.14 \\
\hline 0.41 & 1.09 & 0.85 & 1.16 \\
\hline 0.30 & 1.14 & 0.43 & 1.11 \\
\hline 0.13 & 1.11 & 0.5 & 1.11 \\
\hline 0.50 & 1.12 & 0.33 & 1.18 \\
\hline 1.03 & 1.06 & 0.71 & 1.13 \\
\hline 1.64 & 1.07 & 1.21 & 1.06 \\
\hline 1.42 & 1.14 & 0.57 & 1.09 \\
\hline 1.55 & 1.18 & 1.15 & 1.22 \\
\hline
\end{tabular}

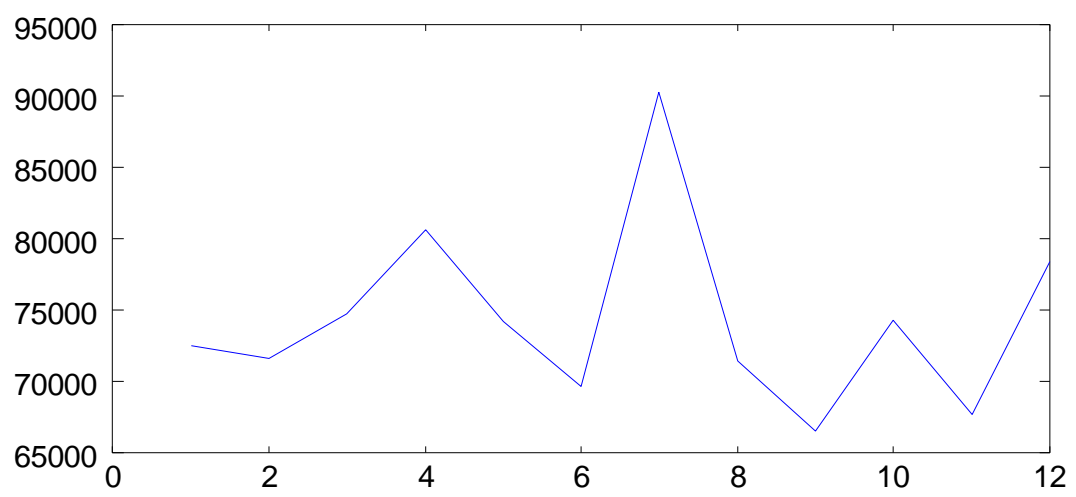

Figure 9. Current account balance of Germany for 2015- 2017 years.

Below we present the results of the quarterly / dollar rate. change in the inflation rate and the France euro

Table 2. Forcast of inflation and currency exchange rates for France economy.

\begin{tabular}{|l|l|l|l|}
\hline \multicolumn{2}{|l|}{ Statistical data } & \multicolumn{2}{l|}{ Forecast } \\
\hline 0.28 & 1.21 & & \\
\hline-0.24 & 1.08 & & \\
\hline 0.21 & 1.12 & -0.31 & 1.08 \\
\hline 0.08 & 1.12 & 0.17 & 1.13 \\
\hline 0.09 & 1.09 & -0.08 & 1.11 \\
\hline-0.04 & 1.14 & 0.08 & 1.14 \\
\hline-0.01 & 1.11 & -0.04 & 1.16 \\
\hline
\end{tabular}




\begin{tabular}{|l|l|l|l|}
\hline 0.28 & 1.12 & 0.01 & 1.09 \\
\hline 0.5 & 1.06 & 0.82 & 1.13 \\
\hline 1.23 & 1.07 & 0.65 & 1.04 \\
\hline 0.88 & 1.14 & 241.8 & 6.42 \\
\hline 0.87 & 1.18 & 0.97 & 1.22 \\
\hline
\end{tabular}

In Table 2, we observe the change of the forcast for the currency exchange rate of France that is adequate to the determining factors. The forcast of the France national currency exchange rate being adequate to the determining factors is changed in correspondence with the current account balance of France presented on the
Figure 10. In considered period the current account balance was negative and the great payments in eight quarter provoked the sharp jump of the inflation and exchange rates at nine quarter.

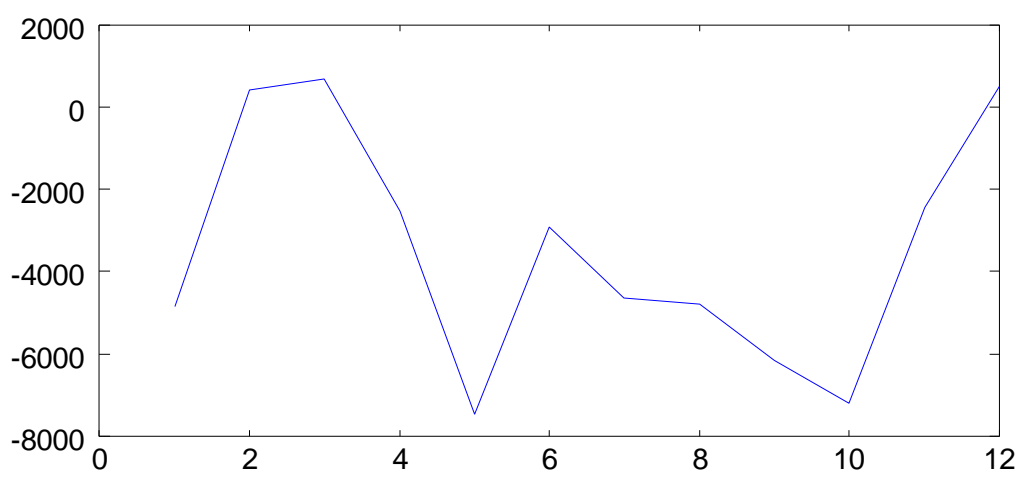

Figure 10. The current account balance of France for 2015 - 2017 years.

In the Table 3, we present the results of the quarterly change in the inflation rate and the euro / USD rate that corresponds to the current account balance presented in Figure 11.

Table 3. Forcast of inflation and currency exchange rates for Italy economy.

\begin{tabular}{|l|l|l|l|}
\hline \multicolumn{3}{|l|}{ Statistical data } & \multicolumn{3}{l|}{ Forecast } \\
\hline 0.09 & 1.21 & & \\
\hline-0.25 & 1.08 & & \\
\hline 0.06 & 1.12 & -0.31 & 1.06 \\
\hline 0.19 & 1.12 & -0.10 & 1.10 \\
\hline 0.16 & 1.09 & 0.13 & 1.14 \\
\hline-0.10 & 1.14 & 0.17 & 1.12 \\
\hline-0.39 & 1.11 & -0.94 & 1.29 \\
\hline-0.02 & 1.12 & -0.26 & 1.14 \\
\hline 0.13 & 1.06 & 1.26 & 1.15 \\
\hline 1.34 & 1.07 & 0.16 & 1.05 \\
\hline 1.50 & 1.14 & -0.37 & 1.08 \\
\hline 1.13 & 1.18 & 1.83 & 1.27 \\
\hline
\end{tabular}

We observe the change of the forcast for the in correspondence with the change of the current currency exchange rate of Italy that is adequate account balance of Italy presented on the Figure to the determining factors. The forcast oscillates 11. 


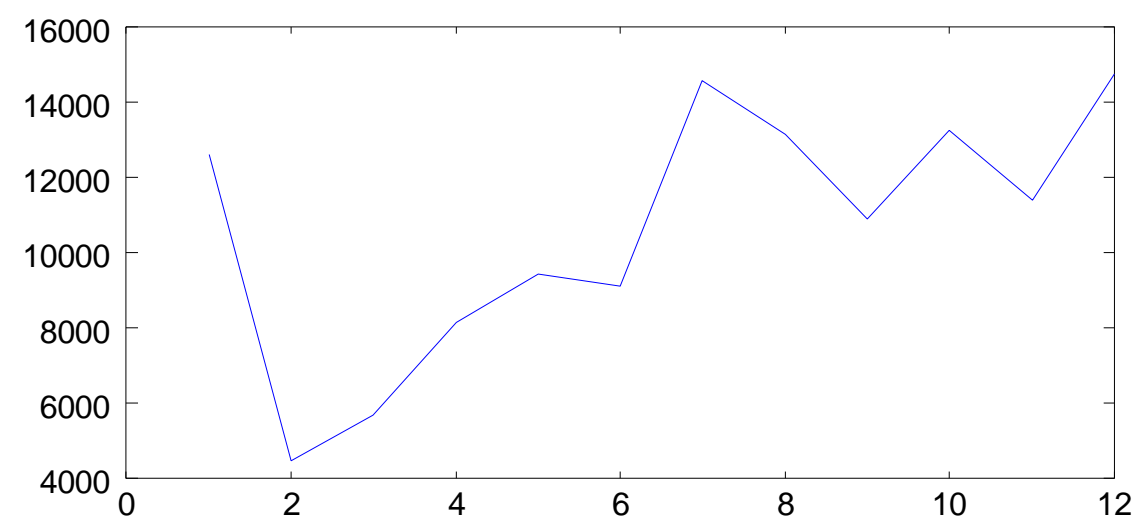

Figure 11. The current account balance of Italy for 2015-2017 years.

The used statistical data relative to the economies of three countries were taken from [10-21].

\section{Conclusions and Results}

In the paper, we formulate the principle of equilibrium of the open economy with its environment: the national currency exchange rate relative to the USA dollar is an indicator of the equilibrium the economy to its environment. Using this principle we establish the canonical money circulation equation in the economy. Based on it the principle of the sustainable economy development is formulated. Outside of this state the economy can be in the state of recession or in the state being close to it. This permit us to classify the equilibrium states of the economy. The quality of the economy equilibrium is determined by parameters of the canonical money circulation equation. To confirm the basic principle that national currency exchange rate relative to the USA dollar is an indicator of the equilibrium the economy to its environment we investigate the dependence of the currency exchange rate on the internal factors determining it.

After that we study the adequacy of the inflation and the currency exchange rates to the determining factors.

For this purpose we assume the inflation and the currency exchange rates is unobservable process that is determined by the stochastic equation depending on the internal factors. For the estimation of this process we use Kalman filter method. On this basis the analysis of Germany, France, Italy economies are given. It is proved that the economy of Germany, France, Italy was in the state of the sustainable economy development during 2015-2017 years. The economy of Italy was close to the unstable state. For every considered country the canonical money circulation equation is constructed. The determination coefficient for all considered economies is not high. It is indication of the fact that these economies is not close connected with the USA economy. The forcast of the currency exchange rate determining by the internal factors differ from the real currency exchange rate at time moment where the current payment balance has the sharp negative falling. This confirms the fact that the currency exchange rate serves as indicator of the economy equilibrium with its environment.

\section{References}

[1]. N.S. Gonchar, O.P. Dovzhyk. (2019) On one criterion for the permanent economy development,Journal of Modern Economy, 2:9, pp. 1-16. . https://doi.org/10.28933/jme-2019-092205

[2]. N. S. Gonchar, A. S. Zhokhin, and W. H. Kozyrski, On peculiarities of Ukrainian economy development, Cybernetics and Systems Analysis, vol. 56, No 3, 2020.

[3]. N.S. Gonchar, A.S. Zhokhin, W.H. Kozyrski,(2015). General Equilibrium and Recession Phenomenon, American Journal of Economics, Finance and Management, 1: 559573.

[4]. N.S. Gonchar, A.S. Zhokhin, (2013). Critical States in Dynamical Exchange Model and 
Recession Phenomenon. Journal of Automation and Information Scince, vol.45, pp.50-58.

[5]. Gonchar N.S. (2008) Mathematical foundations of information economics. - Kiev: Inst. for Theoretical Physics, 468p.

[6]. N.S.Gonchar, A.S.Zhokhin, W.H.Kozyrski.(2015). On Mechanism of Recession Phenomenon. Journal of Automation and Information Sciences, vol. 47, pp. 1-17.

[7]. N. S. Gonchar, W.H. Kozyrski, A.S. Zhokhin, O.P. Dovzhyk, (2018). Kalman Filter in the Problem of the Exchange and the Inflation Rates Adequacy to Determining Factors. Noble International Journal of Economics and Financial Research. vol. 3 (3), pp.31-39. https://www.napublisher.org/pdffiles/NIJEFR-154-31-39.pdf

[8]. R.E. Kalman. (1960). A new approach to linear filtering and prediction problems, Transactions of the ASME, Ser.D, Journal of Basic Engineering, 82: $34-45$.

[9]. Kalman Filtering and Neural Networks. (2001). Edited by Simon Haykin, New York, John Willey \& Sons, Inc., 410p.https://data.oecd.org/price/inflation-cpi.htm

[10]. https://fred.stlouisfed.org/series/CCUSSP01FRQ 650N (France)

[11]. https://fred.stlouisfed.org/series/CCUSSP01ITQ6 $50 \mathrm{~N}$ (Italy)

[12]. https://fred.stlouisfed.org/series/CCUSSP01DEQ $650 \mathrm{~N}$ (German)

[13]. https://www.iea.org/media/statistics

[14]. https://stats.oecd.org/Index.aspx? DataSetCode= QITS\#

[15]. https://read.oecd-ilibrary.org/trade/oecdquarterly-international-trade-statistics/volume2018/issue-3_int_trade-v2018-3-en\#page10 (dates for 2016-2017 years)

[16]. https://read.oecd-ilibrary.org/trade/oecdquarterly-international-trade-statistics/volume2017/issue-3_int_trade-v2017-3-en\#page10 (dates for 2015 year)

[17]. https://read.oecd-ilibrary.org/trade/oecdquarterly-international-trade-statistics/volume2016/issue-4_int_trade-v2016-4-en\#page10 (dates for 2014 year)

[18]. https://tradingeconomics.com/unitedstates/money-supply-m1

[19]. https://countryeconomy.com/deficit

[20]. https://data.oecd.org/interest/long-term-interestrates.htm

[21]. https://countryeconomy.com/gdp 